\title{
Análise política da composiçâa do Conselho Nacional de Saúde (2015/2018)
}

\section{| ${ }^{1}$ Berenice Temoteo da Silva, ${ }^{2}$ Isabel Maria Sampaio Oliveira Lima |}

Resumo: A pesquisa consiste numa análise política das entidades integrantes do Conselho Nacional de Saúde (CNS), eleitas para o triênio 2015/2018, baseada no pensamento estratégico de Testa e nos conceitos de atores estatais e atores societais. Trata-se de um estudo de caso desenvolvido no CNS. Os dados foram produzidos a partir da análise de documentos de três origens relativas ao processo eleitoral do conselho, às suas comissóes intersetoriais e às atas das reuniôes entre 2014 e 2017. Ademais, foram entrevistados os conselheiros atuantes no período da pesquisa. Embora o colegiado seja formado por 144 conselheiros, tendo 48 titulares, um núcleo restrito de conselheiros concentra as principais atividades do CNS e influencia o posicionamento desta institucionalidade. A análise das disputas de poder no CNS permitiu identificar interesses relacionados à luta pelo reconhecimento, à ampliação do lucro no setor saúde e à defesa do SUS constitucional. Apesar da pluralidade de interesses, identificou-se um alinhamento político entre os fóruns em torno da defesa do SUS, buscando ampliar o poder do CNS no processo decisório da política de saúde. Esta convergência revela o quão compelido se acha o CNS dada a atual conjuntura de desmonte da seguridade social.

> Palavras-chave: conselhos de saúde; participação social; análise política.

\author{
${ }^{1}$ Instituto de Saúde Coletiva, \\ Universidade Federal da \\ Bahia. Salvador-BA, Brasil \\ (berenicenfer2007@hotmail.com). \\ ORCID: 0000-0003-095103489 \\ 2 Programa de Pós-Graduação \\ em Família na Sociedade \\ Contemporânea, Universidade \\ Católica do Salvador. Salvador-BA, \\ Brasil (isabelmsol@gmail.com). \\ ORCID: 0000-0002-9833-3721
}

Recebido em: 10/05/2018 Revisado em: 03/01/2019 Aprovado em: 04/02/2019 


\section{Introdução}

O Conselho Nacional de Saúde (CNS) foi originalmente criado como um órgão consultivo do então Ministério da Educação e Saúde Pública no ano de 1937. Era formado por especialistas em saúde pública, indicados pelo ministro e designados pelo presidente da República. A composição e a competência do CNS passaram por modificaçóes sucessivas ao longo dos governos que se seguiram. Entretanto, com o advento da ação política do movimento da Reforma Sanitária Brasileira, em 1990, o CNS, enquanto institucionalidade nacional da área, adquiriu o papel formal de deliberar sobre os rumos da política de saúde e constituiu-se num espaço de participação de representantes da sociedade civil (CORTES et al., 2009).

Apesar da vasta produçáo científica sobre conselhos de saúde no Brasil, evidenciada nas revisóes de literatura (ESPIRIDIÃO, 2014; CAVALCANTI; CABRAL; ANTUNES, 2012; ROLIM; CRUZ; SAMPAIO, 2013; PAIVA; STRALEN; COSTA, 2014), ainda são poucos os estudos sobre o CNS, tendo somente uma pesquisa dedicada à análise da sua composição e dinâmica interna (CORTES, 2009). Esta evidenciou as mudanças na composição do CNS ocorridas até 2006, demonstrando, desde sua criação, a ampliação do número original de conselheiros, bem como de entidades e movimentos sociais em detrimento dos representantes do governo, constatando, ainda, a participação assimétrica dos conselheiros nas discussóes e deliberaçóes do colegiado.

Dessa forma, não há pesquisas recentes sobre o tema e que abordem, ademais, os interesses das entidades que ocupam assento no CNS e a relação desses interesses com as deliberaçôes do colegiado. Assim, o objetivo deste artigo consiste numa análise política da composição do conselho nacional eleita para o período de 2015/2018.

\section{Referencial teórico}

No formato atual, o conselho apresenta uma composição paritária em relação às entidades provenientes da sociedade civil. São $50 \%$ de conselheiros representantes de usuários, enquanto $25 \%$ representam trabalhadores da saúde e $25 \%$, o governo e os prestadores de bens e serviços de saúde (BRASIL, 2012). No entanto, essa classificação adotada pela legislação vigente e discutida nos estudos sobre o tema (KEZH; BÓGUS; MARTINS, 2016; REZENDE; MOREIRA, 2016), circunscreve o usuário como um mero indivíduo consumidor de serviço. Esta inadequação 
quanto à representatividade descaracteriza radicalmente a dinâmica e diversidade política da sociedade brasileira. A natureza política das entidades que disputam os diversos interesses da sociedade no conselho não chega a ser percebida na sua dinâmica. Tampouco a configuração da representatividade possibilita analisar os tensionamentos próprios da relação entre o Estado e a sociedade, materializados no espaço do conselho. Assim, adotaram-se os conceitos de atores societais e estatais, que traduzem expressóes dos interesses mobilizados para ação.

A perspectiva de análise da natureza política das entidades e do processo político existente no âmbito do CNS advém de dois elementos. O primeiro, relativo à própria identificação do vínculo de pertencimento dos atores à esfera estatal ou societal. $\mathrm{O}$ segundo, relativo aos interesses e aos blocos formados em função de alianças estratégicas em torno da defesa de propostas específicas. Essa abordagem crítica, fundamentada no pensamento estratégico de Mário Testa, tem como categoria analítica, o poder, categoria imprescindível na análise política (TEIXEIRA; SILVEIRA, 2016).

A compreensão de atores estatais e atores societais fundamenta-se no conceito gramsciano de Estado, isto é, aquele que acomoda, além da sociedade política, a sociedade civil como parte do Estado. A primeira, formada pelo conjunto de mecanismos através dos quais a classe dominante detém o monopólio legal da coerção, aqueles habitualmente identificados como governo. Já a sociedade civil, por sua vez, é formada como uma decisiva arena da luta de classes, na qual os diferentes grupos sociais lutam para conservar ou conquistar a hegemonia (COUTINHO, 2011).

Nesse sentido, os atores estatais são aqueles que ocupam cargos de direção em órgãos do Executivo e em organizaçôes governamentais. São também os que ocupam os demais poderes da República e, ainda, os integrantes da sociedade civil que agem construindo consensos para manter a hegemonia da classe dominante. Alinham-se, dessa forma, os atores estatais para que a ação estatal possa ocorrer, inclusive, fora do espaço formal da máquina do Estado. Já os atores societais pertencem à sociedade civil e são classificados de forma genérica em atores societais sociais e atores societais de mercado (CORTES et al., 2009).

O Conselho Nacional de Saúde conta com a ação estratégica de ambos os atores estatais e societais cujos interesses, em determinados momentos, podem ser conflitantes, ainda que sejam capazes de estabelecimento de determinadas alianças. Assim, do ponto de vista dos interesses defendidos por esses atores na arena interna 
do conselho, admite-se que os atores governamentais se alinham aos propósitos de legitimidade, crescimento (ampliação das açôes e serviços de saúde) ou mudança (modelo de atenção), defendidos pelo governo para o setor saúde, sobretudo para garantir a reprodução da classe dominada (TESTA, 2004, p. 111; FEDERICO, 2015, p 215). Enquanto os atores societais do mercado, embora se envolvam nos debates sobre os problemas e necessidades de saúde, guardam como a principal intencionalidade que rege a sua ação política a sua racionalidade econômica, cujos imperativos são a produtividade e o lucro (CORTES, 2010).

Os atores societais que não representam o governo ou o mercado, portanto atores sociais com assento no conselho, carregam um conjunto diversificado de interesses, que, em grande medida, podem estar vinculados a dois movimentos identitários. O primeiro destes movimentos é considerado afirmativo, aquele que clama por justiça social e cujas reivindicaçóes se baseiam no princípio de equidade. $\mathrm{O}$ outro movimento é identificado a partir da luta pelo reconhecimento (FRASER, 2007). Este reconhecimento integraria elementos relativos tanto à importância da categoria profissional para o setor saúde, quanto o próprio reconhecimento de determinadas particularidades, sejam étnicas, de gênero e dos portadores de patologias e deficiências nas políticas de saúde (BAHIA, 2015).

\section{Método}

Trata-se de uma pesquisa qualitativa do tipo estudo de caso sobre a composiçáo do Conselho Nacional de Saúde eleito para o triênio 2015/2018. O período do estudo foi de 2014 a 2017. O recorte temporal adotado neste estudo inicia-se em 2014 devido a uma circunstância de natureza igualmente fática e política, que, embora pontual, reverberou, trazendo elementos emblemáticos da composição do CNS. Refere-se à saída de entidades médicas do CNS. Enquanto o período final de 2017, termo final deste artigo, deve-se à necessidade de finalizar a produção de dados para proceder à redaçáo da tese.

Os dados foram produzidos a partir de 27 entrevistas semiestruturadas realizadas com 22 conselheiros pertencentes à gestão 2015/2018 e cinco participantes-chave que foram conselheiros no período 2012/2015. Foram analisados 62 documentos, sendo 26 relacionados ao processo eleitoral do conselho e de suas comissóes intersetoriais e atas de 36 reunióes. Destas, cinco (as de números 254, 261-264, respectivamente) 
referiam-se aos debates ocorridos em 2014 acerca da participação das entidades médicas no conselho, oito $(267,270-274,276,58)$, ao processo eleitoral do conselho, que aconteceu em 2015, e 23 atas produzidas de janeiro de 2016 a outubro de 2017, que registravam a atuação da composição eleita para o triênio 2015/2018. A seleção das atas de 2014 e 2015 se deu a partir dos resumos executivos das reunióes ocorridas naqueles anos. Os documentos foram lidos na íntegra. O instrumento de coleta de dados nos documentos consistiu numa matriz contendo as seguintes variáveis: identificação da ata; tipo, número e data da reuniáo; categoria - composição do conselho; debate ocorrido; e deliberação. As variáveis sobre assiduidade das entidades, coordenação de pauta, reestruturação das comissôes e coordenação das comissōes intersetoriais foram verificadas nas atas sobre a atuação das entidades eleitas para o triênio em estudo.

A duração das reuniôes ordinárias analisadas foi de dois e três dias, enquanto as de caráter extraordinário tiveram a duração de um dia. Assim, as 23 reuniōes a partir das quais foi aferida a assiduidade das entidades referem-se a 44 dias de encontro. As atas examinadas foram provenientes das seguintes reuniōes: $277^{a}$ à 298ª as ordinárias e 59a à 61ª as extraordinárias. A exceção consiste na ata 291, de março de 2017, em cujo registro constava somente o resumo executivo.

A análise dos documentos foi subsidiada pelas seguintes categorias analíticas e operacionais: representantes estatais (governamentais); representantes societais (mercado, social) e poder (oponente, aliado, disputa, consenso). Foram considerados atores estatais os representantes governamentais da gestão em saúde; os atores societais de mercado estão identificados pela categoria de prestadores de bens e serviços de saúde; e os atores societais sociais foram denominados pelas categorias de entidades de trabalhadores e profissionais de saúde; trabalhadores de outras áreas; entidades de portadores de patologia e Pessoa com Deficiência (PcD); entidades de gênero e étnicas; associaçóes comunitárias, movimentos sociais e ONG; e a categoria de representaçôes religiosas. $\mathrm{O}$ agrupamento dos atores em categorias parte da identificação dos grupos sociais de maior influência no setor saúde (CORTES, et al., 2009).

Tais categorias possibilitaram a análise estratégica da composição do conselho eleita para o período de 2015/2018. Todos os documentos são de domínio público e encontram-se disponíveis no site do CNS (http://conselho.saude.gov.br/). O projeto foi aprovado pelo Comitê de Ética em Pesquisa do Instituto de Saúde Coletiva da Universidade Federal da Bahia, sob o parecer de número 2.235.550. Os pesquisados assinaram o Termo de Consentimento Livre e Esclarecido. 


\section{Resultados e Discussão}

O plenário do conselho consiste em um espaço no qual as representaçóes estatais e societais realizam debates, defendem propostas e disputam a hegemonia de seus interesses. As entidades provenientes das representaçôes sociais se articulam em fóruns criados especialmente para atuar no conselho. Seus encontros precedem as reunióes ordinárias do conselho no intuito de estabelecer as estratégias que serão utilizadas, os posicionamentos e argumentos que serão defendidos nos debates do colegiado.

Os trabalhadores da saúde, com exceção da categoria médica, representados pelas federaçôes de caráter sindical, conselhos de profissão e entidades da comunidade científica integram o Fórum dos Trabalhadores e Trabalhadoras da Saúde (FENTAS). Enquanto as demais entidades societais, exceto as representaçóes de mercado, organizam-se em torno do Fórum dos Usuários. Tais fóruns têm a finalidade de constituir alinhamento político e fortalecer a coerência entre os segmentos participantes.

A escolha dos conselheiros para atuar durante o triênio 2015/2018 no CNS ocorreu em novembro de 2015. O país estava em momento de complexa conjuntura marcada pela recessão econômica. No cenário nacional emergiam diferentes iniciativas do poder Legislativo com forte conteúdo regressivo para as políticas sociais. Caracterizava-se clara ameaça à governabilidade do poder Executivo e à continuidade do governo federal, que fora eleito democraticamente. Estavam sendo ameaçados tanto a própria democracia quanto o Estado de direito (GONH, 2015; FIGUEIRAS, 2015; GADELHA, 2015; COSTA, 2015).

\section{Processo eleitoral}

O processo eleitoral do CNS para o período de 2015/2018 começou a ser debatido em plenário na reunião de junho de 2015. A discussão se deu, principalmente, em torno de dois aspectos, o político e o burocrático. No primeiro caso, foi proposto que as entidades, que então pleiteassem vagas, apresentassem uma carta de intenção contendo o seu compromisso com a defesa do SUS. A justificativa dessa proposta consistia em evitar que entidades com alinhamento político conservador fizessem parte do colegiado. No entanto, a proposta foi vencida na questão do mérito e não chegou ao menos a ser votada. Além de carecer de respaldo legal, a simples apresentação de uma carta de intençôes não garantiria aliados para o projeto de defesa do SUS. 
Dentre os elementos formais, havia a preocupaçáo de que novas entidades mobilizadas durante a $15^{\mathrm{a}}$ conferência nacional de saúde passassem a integrar o conselho, renovando a composição do colegiado. Contudo, o debate mais persistente se deu em torno dos documentos necessários para comprovar a abrangência nacional da entidade. Desde 2006, vigora o Decreto n. 5.839, que estabelece, entre outros aspectos, a participação dos movimentos sociais e entidades nas eleições do conselho nacional de saúde condicionada à comprovação de sua existência em pelo menos nove estados da federação, distribuídos, no mínimo, em três regióes brasileiras (BRASIL, 2006).

Esse debate ganhou espaço no plenário em quatro reunióes ordinárias (atas 270, 271, 273 e 274) e pode estar relacionado à dificuldade, sobretudo dos movimentos sociais, de comprovarem sua atuação. Nesse ínterim, surgiu a proposta de reformular as normativas referentes à composição e ao papel do conselheiro, porém a única alteração que sucedeu diz respeito à representação indígena, para a qual, devido a sua forma peculiar de organização, passou a ser exigida a comprovação da atuação mínima somente em uma região geográfica do país.

O processo eleitoral ocorre somente entre os representantes societais. Assim, dos 144 assentos do conselho (48 titulares e 96 primeiros e segundos suplentes), 120 são abertos para disputa eleitoral, sendo 40 para as vagas de titulares. Para o triênio 2015/2018, houve 161 entidades inscritas, sendo nove representantes de mercado e 152 representantes sociais. No primeiro momento, foram selecionadas 99 entidades para concorrer às eleiçôes. $\mathrm{O}$ critério mais recorrente, que inabilitou as inscriçôes tanto das representantes sociais quanto daquela de mercado, consistiu naquele mais debatido pelo plenário, ou seja, a abrangência geográfica de sua atuação. Com isso, o prazo de envio dos documentos foi prorrogado e 120 entidades foram habilitadas, destas, 106 compareceram e 90 foram eleitas.

A mesa diretora, incluindo o presidente do conselho, foi eleita pelo plenário. Três conselheiros de entidades sociais lançaram candidatura à presidência, sendo um integrante do FENTAS e dois, do Fórum dos Usuários. O FENTAS lançou a Federação Nacional dos Farmacêuticos (FENAFAR), uma de suas representaçôes sindicais, e o Fórum dos Usuários registrou a candidatura do Movimento de Reintegração das Pessoas Atingidas pela Hanseníase (MORHAN), da categoria dos movimentos de portadores de patologias, e uma representação sindical, a Nova Central Sindical dos Trabalhadores (NCST). 
Para lograr a maioria dos votos do conselho, o FENTAS necessita atuar em bloco e construir acordos com outros segmentos, pois dispóe somente de um quarto das entidades. Essa estratégia de buscar apoiadores foi utilizada na disputa pela presidência do colegiado, como pode ser constatado na seguinte fala:

A eleição [do presidente do CNS] foi uma grande costura que uniu governo, que uniu os prestadores em torno do nome dele. [Ele] não era um dos nomes que fosse o mais forte, tinha gente que podia ser mais forte do que ele, mas isso conseguiu se estruturar (INFORMANTE 1 - GOVERNO).

O Fórum dos Usuários agrega a metade dos conselheiros. Assim, o lançamento de um único candidato com o apoio desse fórum significa uma chance real de ganhar uma disputa. Contudo, os conflitos internos não foram superados e o lançamento de dois candidatos enfraqueceu ambos os pleitos. A disputa em torno de interesses diversos, mesmo que não sejam necessariamente conflitantes, no interior do Fórum dos Usuários, foi percebida e utilizada estrategicamente pelos representantes governamentais, como apontado na seguinte fala:

Os usuários já são mais dispersos porque eles têm tantas demandas, são tantas as linhas que para eles se constituírem como um bloco é uma coisa muito complicada. É tanto que eles são mais fáceis de você rachar do que os trabalhadores porque os trabalhadores trabalham numa linha de uma corporação (INFORMANTE 1 - GOVERNO).

Seja pelo cálculo político acerca da viabilidade de ganhar a eleição, ou ainda devido ao estabelecimento de alianças estratégicas, o Movimento de Reintegração das Pessoas Atingidas pela Hanseníase (MORHAN) e a Nova Central Sindical dos Trabalhadores (NCST) retiraram o pleito e a Federação Nacional dos Farmacêuticos (FENAFAR) tornou-se, dessa maneira, a única concorrente. Foi diante desta dinâmica que a FENAFAR conquistou a presidência do CNS para o triênio 2015/2018. A mesa diretora está composta por oito entidades, sendo seis sociais e duas representações governamentais. Assim, as organizaçóes do mercado não fazem parte da mesa no triênio 2015/2018, conforme apresentado no quadro 1 . 
Quadiro 1. Composição da mesa diretora do Conselho Nacional de Saúde - 2015/2018

\begin{tabular}{|c|c|}
\hline Representaçóes Sociais (06) & $\begin{array}{c}\text { Representaçóes } \\
\text { Governamentais (02) }\end{array}$ \\
\hline Presidente do CNS & \multirow[t]{2}{*}{ Ministério da Saúde (MS) } \\
\hline Federação Nacional dos Farmacêuticos (FENAFAR) & \\
\hline Associação Brasileira de Ensino em Fisioterapia (ABENFISIO) & \multirow{5}{*}{$\begin{array}{l}\text { Conselho Nacional dos } \\
\text { Secretários de Saúde } \\
\text { (CONASS) }\end{array}$} \\
\hline Confederação Nacional dos Bispos do Brasil (CNBB) & \\
\hline Central Única de Trabalhadores (CUT) & \\
\hline $\begin{array}{l}\text { Coordenação das Organizações Indígenas da Amazônia } \\
\text { Brasileira (COIAB) }\end{array}$ & \\
\hline $\begin{array}{l}\text { Federação Nacional das Associaçóes de Celíacos do Brasil } \\
\text { (FENACELBRA) }\end{array}$ & \\
\hline
\end{tabular}

Fonte: elaboração própria.

\section{Composição do CNS}

O Conselho Nacional de Saúde é composto por 48 conselheiros titulares, e destes, somente oito são representantes estatais. As entidades provenientes da sociedade civil ocupam $83,3 \%$ do plenário, sendo $75 \%$ destas compostas por entidades societais sociais, conforme apresentado na tabela 1.

Tabela 1. Número de Conselheiros Nacionais de Saúde por representantes titulares societais e estatais - 2015/2018

\begin{tabular}{lcclccc}
\hline Tipo de representantes & F & $\%$ & Tipo de representantes & F & $\%$ \\
\hline Societais & 40 & 83,3 & Sociais & 36 & 75 \\
& & & Mercado & 4 & 8,3 \\
Estatal & 8 & 16,7 & Governamental & 8 & 16,7 \\
\hline Total & 48 & 100 & Total & 48 & 100 \\
\hline
\end{tabular}

Fonte: elaboração própria. 
Os 40 conselheiros titulares representantes da sociedade civil estão distribuídos nas seguintes categorias: quatro prestadores de bens e serviços representando as entidades do mercado; 12 entidades de trabalhadores e profissionais de saúde; cinco de trabalhadores de outras áreas; oito entidades de portadores de patologia e Pessoa com Deficiência (PcD); quatro entidades de gênero e étnicas; cinco de associaçóes comunitárias, movimentos sociais e ONG; e duas de representaçôes religiosas, como apresentado no quadro 2 .

Quadro 2. Composição do CNS por representantes titulares estatais e societais 2015/2018

\begin{tabular}{|c|c|c|}
\hline 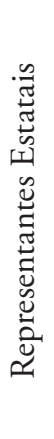 & $\begin{array}{l}\text { Governamentais } \\
(08)\end{array}$ & $\begin{array}{l}\text { - Ministro da Saúde - MS } \\
\text { - Ministro da Saúde - MS } \\
\text { - Ministro da Saúde - MS } \\
\text { - Ministro da Saúde - MS } \\
\text { - Ministério do Trabalho e da Previdência Social } \\
\text { - Ministro da Saúde - MS } \\
\text { - Conselho Nacional dos Secretários de Saúde (CONASS) } \\
\text { - Conselho Nacional dos Secretários Municipais de Saúde } \\
\text { (CONASEMS) }\end{array}$ \\
\hline & $\begin{array}{l}\text { Prestadores de } \\
\text { Bens e Serviços } \\
(04)\end{array}$ & $\begin{array}{l}\text { - Confederação Nacional da Indústria (CNI) } \\
\text { - Confederaçáo Nacional de Saúde (CNS) } \\
\text { - Confederaçáo Nacional do Comércio (CNC) } \\
\text { - União Nacional das Instituiçóes de Autogestão em Saúde (UNIDAS) }\end{array}$ \\
\hline 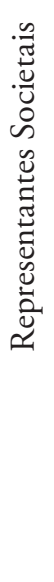 & $\begin{array}{l}\text { Profissionais e } \\
\text { Trabalhadores } \\
\text { da Saúde (12) }\end{array}$ & $\begin{array}{l}\text { - Federação Nacional dos Assistentes Sociais (FENAS) } \\
\text { - Confederação Nacional dos Trabalhadores na Saúde (CNTS) } \\
\text { - Federação Interestadual dos Odontologistas (FIO) } \\
\text { - Federação Nacional dos Farmacêuticos (FENAFAR) } \\
\text { - Associação Brasileira de Ensino em Fisioterapia (ABENFISIO) } \\
\text { - Associação Brasileira de Saúde Coletiva (ABRASCO) } \\
\text { - Associação Brasileira de Nutrição (ASBRAN) } \\
\text { - Associação Brasileira de Enfermagem (ABEn) } \\
\text { - Conselho Federal de Nutricionistas (CFN) } \\
\text { - Conselho Federal de Farmácia (CFF) } \\
\text { - Conselho Federal de Medicina Veterinária (CFMV) } \\
\text { - Conselho Federal de Fisioterapia e Terapia Ocupacional (COFFITO) }\end{array}$ \\
\hline
\end{tabular}




\begin{tabular}{|c|c|c|}
\hline \multirow{5}{*}{ 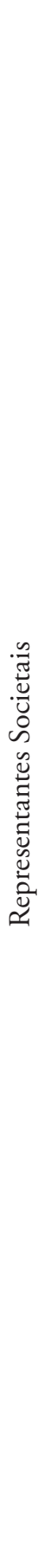 } & $\begin{array}{l}\text { Trabalhadores } \\
\text { de outras áreas } \\
(05)\end{array}$ & $\begin{array}{l}\text { - Confederação Nacional dos Trabalhadores na Agricultura } \\
\text { (CONTAG) } \\
\text { - Sindicato Nacional dos Aposentados, Pensionistas e Idosos da } \\
\text { Força Sindical (SINDINAPI/FS) } \\
\text { - Central Única dos Trabalhadores (CUT) } \\
\text { - Força Sindical (FS) } \\
\text { - Nova Central Sindical dos Trabalhadores (NCST) }\end{array}$ \\
\hline & $\begin{array}{l}\text { Entidades de } \\
\text { portadores } \\
\text { de patologia } \\
\text { e Pessoa com } \\
\text { Deficiência (09) }\end{array}$ & $\begin{array}{l}\text { - Organização Nacional dos Cegos do Brasil (ONCB) } \\
\text { - Associação Brasileira de Autismo (ABRA) } \\
\text { • Federação Brasileira das Associaçóes de Síndrome de Down (FBASD) } \\
\text { - Articulaçáo Nacional de Luta Contra a Aids (ANAIDS) } \\
\text { - Federação Nacional das Associaçóes de Pessoas com Doenças } \\
\text { Falciformes (FENAFAL) } \\
\text { - Federação Nacional das Associaçóes de Celíacos do Brasil } \\
\text { (FENACELBRA) } \\
\text { - Movimento de Reintegração das Pessoas Atingidas pela } \\
\text { Hanseníase (MORHAN) } \\
\text { - Organizaçáo Nacional de Entidades de Deficientes Físicos } \\
\text { (ONEDEF) } \\
\text { - Federação Brasileira de Instituiçóes Filantrópicas de Apoio à Saúde } \\
\text { da Mama (FEMAMA) }\end{array}$ \\
\hline & $\begin{array}{l}\text { Entidades } \\
\text { de Gênero } \\
\text { e Étnicas - } \\
\text { População } \\
\text { Negra e } \\
\text { Indígena (04) }\end{array}$ & $\begin{array}{l}\text { - Associação Brasileira de Lésbicas, Gays, Bissexuais, Travestis e } \\
\text { Transexuais (ABGLT) } \\
\text { - Rede Nacional Lai Lai Apejo } \\
\text { - Organizaçóes Indígenas da Amazônia Brasileira (COIAB) } \\
\text { - Articulaçáo dos Povos Indígenas da Região Sul - ARPINSUL }\end{array}$ \\
\hline & $\begin{array}{l}\text { Associações } \\
\text { Comunitárias, } \\
\text { Movimentos } \\
\text { Sociais e ONG } \\
(04)\end{array}$ & $\begin{array}{l}\text { - Confederação Nacional das Associações de Moradores (CONAM) } \\
\text { - Movimento Nacional de População de Rua (MNPR) } \\
\text { - Uniāo Brasileira de Mulheres (UBM) } \\
\text { - Associação Nacional de Pós-Graduandos (ANPG) }\end{array}$ \\
\hline & $\begin{array}{l}\text { Organizaçóes } \\
\text { religiosas - } \\
\text { Igreja católica } \\
(02)\end{array}$ & $\begin{array}{l}\text { - Conferência Nacional dos Bispos do Brasil (CNBB) } \\
\text { - Pastoral da Saúde Nacional }\end{array}$ \\
\hline
\end{tabular}

Fonte: elaboração própria. 
Os assentos do CNS foram ocupados pelos grupos de interesses mais organizados da sociedade brasileira contemporânea, que mantêm uma rede de relaçóes com o conselho e foram mobilizados durante a $15^{\mathrm{a}}$ conferência nacional de saúde (COELHO, 2015). Assim, o plenário do conselho acolheu 17 novas entidades societais para atuar no período 2015/2018, sendo três para as vagas de titulares. O percentual de renovação foi de 20,4\%, não atingindo o mínimo de 30\% recomendado pela Resolução 453/2012. Duas categorias se destacam na renovação do conselho. São as associações comunitárias, movimentos sociais ou ONG e os profissionais e trabalhadores da saúde, cada uma destas com cinco novas entidades representativas. Em relação aos conselheiros indicados pelas representaçóes eleitas, 52 assumiram, pela primeira vez, uma cadeira no Conselho Nacional de Saúde, dos quais 12 foram para titulares.

Os representantes estatais possuem oito vagas titulares, que, além do Ministério da Saúde, do CONASS e do CONASEMS, podem ser ocupadas por outros ministérios. No triênio 2015/2018, o Ministério da Saúde ocupa cinco das oito cadeiras titulares e somente o Ministério do Trabalho e da Previdência Social ocupava assento no CNS. A partir da indicação de novos conselheiros governamentais em julho de 2016, inclusive do recém-empossado ministro da Saúde Ricardo Barros, o Ministério da Educação substituiu o MTPS, ação que desagradou representantes sindicais.

A participação dos ministérios no conselho vem diminuindo gradativamente a cada triênio e as vagas governamentais sendo ocupadas pelo Ministério da Saúde. No período entre 1990/1992, a metade das representaçóes estatais era composta por outros ministérios. Assim, os ministérios da Educação; da Economia, Fazenda e Planejamento; da Ação Social; e do Trabalho e Previdência Social compartilhavam com o CONASS, o CONASEMS e o Ministério da Saúde os oito assentos governamentais. Já no período 2003/2006, o Ministério da Saúde ocupava três cadeiras no conselho e havia a participação de outros três ministérios, o da Educação; da Previdência Social; e do Trabalho e Emprego (CORTES et al., 2009).

A mudança de governo e de seus respectivos ministros da Saúde repercutiu na composição política do CNS. Em 2014, o órgão gestor da saúde na esfera federal era dirigido pelo ministro Arthur Chioro, médico sanitarista do Partido dos Trabalhadores (PT), integrante da mesma coalizão política do governo federal. Em meio à crise política que culminou com a aceitação do pedido de afastamento da presidente da República Dilma Rouseff, do PT, pelo Congresso Nacional, no final de 2015, o comando do ministério foi substituído pelo deputado Marcelo Castro, 
médico psiquiatra do então Partido Movimento Democrático Brasileiro (PMDB), atual Movimento Democrático Brasileiro (MDB). O ministério foi cedido à bancada do PMDB pela então presidente Dilma Rouseff, em uma dinâmica política de apoio no Congresso Nacional, servindo como uma substancial moeda de troca política em nome da governabilidade (ESCOREL, 2015).

Em maio de 2016, no início do governo do presidente interino Michel Temer, do PMDB, foi indicado um novo ministro para o setor saúde, o engenheiro civil e deputado do Partido Progressista (PP) Ricardo Barros. Este deixou o cargo para disputar as eleiçóes de 2018, sendo substituído por Gilberto Occhi, advogado filiado ao PP, ex-presidente da Caixa Econômica Federal, indicado pelo partido para assumir a pasta. Assim, a substituição sistemática dos conselheiros indicados pela gestão entre 2014 e 2017 não foi circunstancial, pois nesses quatro anos, ministros de distintas plataformas político-ideológicas conduziram o Ministério da Saúde.

Os profissionais médicos ocupam somente uma cadeira na segunda suplência através da Federação Nacional dos Médicos (FENAM), uma entidade de caráter sindical. $\mathrm{O}$ antagonismo enfrentado pela categoria médica no CNS em torno do Projeto de Lei no 268/2000, conhecido como Ato Médico, bem como os tensionamentos gerados no debate acerca do movimento pelo Programa Mais Médicos no ano de 2013, fizeram com que o Conselho Federal de Medicina (CFM), a Associação Médica Brasileira (AMB) e a FENAM se ausentassem do colegiado.

$\mathrm{Na}$ ocasião, o plenário aprovou um documento recomendando à Presidência da República que vetasse os incisos do referido Projeto de Lei que garantiam exclusividade do ato médico em atividades até então desenvolvidas por outros profissionais de saúde (ata 247). O conselho também apoiou a criação do programa Mais Médicos, cujo objetivo foi ampliar a quantidade desses profissionais, sobretudo nas regiôes mais longínquas do país (BRASIL, 2013). Tais profissionais se colocaram como fortes opositores ao programa com críticas em torno da liberação da revalidação de diplomas estrangeiros, da questão trabalhista e da ampliação das vagas para o curso de medicina (RIBEIRO, 2015).

O debate do 'Mais Médicos' foi intenso dentro do CNS, com o CNS apoiando o governo para quebrar a hegemonia de uma relação corporativa, de mudar a face da atenção à saúde na atenção básica. Mexer não só com a questão da assistência, mas mexer com a formação, mexer com o processo de interiorização dos profissionais. Mexer com as relaçóes corporativas, mexer com outros ministérios que é outro problema porque tinha que mexer com um MEC por conta da formação médica (INFORMANTE I - GOVERNO). 
O afastamento por mais de um ano das entidades médicas do conselho ganhou espaço no debate de cinco reuniōes ordinárias no ano de 2014 (atas 254, 261, 262, 263, 264). Notificaçôes foram emitidas para as entidades e somente a FENAM se manifestou e indicou um novo representante. Dessa forma, foi declarada a vacância para a vaga do CFM, conforme norma regimental. No ano seguinte, aberto o processo eleitoral para o triênio 2015/2018, o CFM não se candidatou e a AMB se inscreveu, porém não compareceu para votação.

\section{Dinâmica do funcionamento do CNS}

Um significativo indicador da correlação de forças existente no conselho está na identificação daquelas entidades que são majoritárias. Além deste elemento, considera-se que a assiduidade dos seus conselheiros titulares nas reunióes e a coordenaçáo dos pontos de pauta convergem em impacto no modus operandi da correlação de forças. Entre as 90 entidades eleitas para compor o CNS, 24 são sindicais, sendo nove titulares. A segunda maior representação é da categoria de portadores de patologias e $\mathrm{PcD}$ com 20 entidades eleitas, e destas, nove são titulares. Dessa forma, a organização mais representada consiste nos sindicatos, os quais pertencem tanto à categoria de profissionais e trabalhadores de saúde quanto à categoria de trabalhadores de outras áreas.

$\mathrm{Na}$ tabela 2 está apresentada a frequência das entidades em 44 dias de reunião agrupadas em intervalos de 15 dias, de acordo com as categorias e os tipos de atores. Entre as 48 entidades titulares, a metade marcou presença em 31 dias ou mais de reuniāo, ou seja, a assiduidade de $50 \%$ dos conselheiros foi igual ou superior a $70,5 \%$. Destes, 11 representantes societais sociais estiveram em $40(90,1 \%)$ dias ou mais de reunião, com destaque para as categorias de trabalhadores de outras áreas e de profissionais e trabalhadores da saúde, com quatro representantes de cada. Em ambas as categorias, a governamental e a de mercado, somente um conselheiro de cada esteve presente em mais de $70 \%$ dos dias de reunião. 
Tabela 2. Número de dias de reunião, por categoria de entidades do CNS, segundo os tipos de atores: sociais, de mercado e governamentais, 2016-2017

\begin{tabular}{|c|c|c|c|c|c|}
\hline \multicolumn{2}{|r|}{$\begin{array}{c}\text { Números de dias de reuniáo aos quais os } \\
\text { conselheiros compareceram }\end{array}$} & $0-15$ & $16-30$ & $31-44$ & Total \\
\hline & \multicolumn{5}{|l|}{ Categoria de Entidades } \\
\hline \multirow{6}{*}{$\begin{array}{l}\frac{n}{\pi} \\
\frac{\pi}{0} \\
\dot{0}\end{array}$} & Portadores de patologia e $\mathrm{PcD}$ & 2 & 3 & 4 & 9 \\
\hline & Profissionais e trabalhadores da saúde & 0 & 4 & 8 & 12 \\
\hline & Trabalhadores de outras áreas & 0 & 0 & 5 & 5 \\
\hline & Entidades de gênero e étnica & 0 & 2 & 2 & 4 \\
\hline & Associação de moradores, movimento social e ONG & 0 & 2 & 2 & 4 \\
\hline & Entidade religiosa & 0 & 1 & 1 & 2 \\
\hline 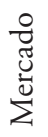 & Prestadores de bens e serviços & 2 & 1 & 1 & 4 \\
\hline \multirow[t]{2}{*}{$\begin{array}{l}0 \\
\Xi \\
0 \\
0 \\
0 \\
0\end{array}$} & Gestores & 6 & 1 & 1 & 8 \\
\hline & Total & 10 & 14 & 24 & 48 \\
\hline
\end{tabular}

Fonte: elaboração própria.

A partir da variável denominada coordenação dos pontos de pauta verificouse que, nos 44 dias de reunião, foram debatidos temas em 189 pontos de pauta, dos quais 174 (92\%) foram coordenados pelos conselheiros da mesa diretora. Entre os oito componentes da mesa, quatro sozinhos conduziram o debate $135(71,4 \%)$ vezes, sendo dois da categoria de profissionais e trabalhadores da saúde (FENAFAR e ABENFISIO), um da igreja (CNBB) e um da categoria de trabalhadores de outras áreas (CUT). Registrou-se, ainda, a participação de outras 11 entidades conduzindo a pauta 15 vezes. Os atores estatais estiveram à frente de 24 (12,7\%) discussóes, sendo que no período analisado nenhum representante do mercado coordenou ponto de pauta.

As comissões intersetoriais do CNS passaram por um processo de reformulação e de eleição. $O$ trabalho das comissóes, compostas basicamente por entidades titulares e suplentes, ou ainda aquelas que concorreram às eleiçóes do CNS, consiste 
em debater políticas, normas e programas de interesse da saúde e submeter suas recomendações à apreciação do plenário, subsidiando, dessa forma, a atuação do conselho (BRASIL, 1990, Lei n. 8.080/1990). No entanto, entre janeiro de 2014 até a época do debate da reestruturação das comissôes, em abril de 2016, constatouse que das 26 comissóes existentes no conselho, somente três se mantiveram constantemente atuantes: a Comissão Intersetorial de Orçamento e Financiamento (COFIN), a Comissão Intersetorial de Recursos Humanos - CIRH e a Comissão Nacional de Ética em Pesquisa (CONEP).

Essas comissóes, especialmente a COFIN e a CIRH, exercem um papel político relevante nas deliberaçóes do CNS, já que seus pareceres são constantemente aprovados pelo plenário do conselho nacional. A ativa participaçáo política dos membros da COFIN em torno de uma postura de negociação com o plenário, bem como a consistência técnica dos seus pareceres resultam na aprovação de suas recomendaçóes relativas aos temas de financiamento e de planejamento do SUS, transformando-se em recomendaçôes do conselho aos Poderes da República e até em denúncias acerca da situação do subfinanciamento público da saúde.

A inércia das comissóes foi questionada no plenário em maio de 2015 e o debate apontou para a necessidade de elaborar uma estratégia para fortalecer o potencial desses espaços. Antes mesmo de ser formulada qualquer proposta, em março de 2016, foi pautada a recomposição da Comissão Intersetorial de Saúde Mental (CISM). A indicação de um coordenador da área de saúde mental do Ministério da Saúde, feita pelo então ministro Marcelo Castro, na pessoa de um ex-diretor de hospital psiquiátrico privado, fechado sob denúncias de maus-tratos aos pacientes, foi interpretada como uma possibilidade de retrocessos na área, gerando forte antagonismo dos defensores da reforma psiquiátrica. Tal circunstância motivou a constituição provisória da CISM do CNS, sobretudo para contribuir com a mediação desse conflito. Pouco tempo depois, em dezembro de 2017, uma nova política nacional de saúde mental, marcada por incentivos à hospitalização, inclusive em hospitais psiquiátricos, foi aprovada pela Comissão Intergestora Tripartite (CIT), sem a participação do CNS (BOLETIM OAPS, 2018).

Afora a reestruturação circunstancial da CISM, a mesa diretora apresentou ao plenário a proposta de reformulaçáo das comissôes em abril de 2016, tendo como principal mudança a redução de 26 para 18 comissóes. Para tal finalidade, 11 comissôes foram aglutinadas em cinco e outras duas foram extintas, a de trauma 
e violência e a de comunicação e informação em saúde. $\mathrm{O}$ argumento utilizado para justificar essa alteração consistiu no objetivo de agregar forças para enfrentar a difícil conjuntura pela qual o país está passando e, dessa maneira, potencializar sua atuação, otimizando gastos para a manutenção do funcionamento das comissôes.

A proposta partiu do consenso da mesa e contou com o apoio, principalmente, de representantes estatais e de mercado. As manifestaçóes contrárias à proposta da mesa advieram dos representantes societais sociais, sobretudo de conselheiros integrantes daquelas comissôes que estavam sendo extintas ou condensadas. A perda de espaço para ação política, bem como da visibilidade e reconhecimento de demandas historicamente negligenciadas, foi o pretexto que sustentou a oposição de algumas entidades à fusão das comissões. Ao longo do debate, as estratégias de convencimento dos apoiadores da proposta da mesa diretora de reduzir as comissóes foram suficientes para conquistar a maioria no plenário, tendo sido aprovada conforme apresentado no quadro 3.

\section{Quadro 3. Recomposiçẫo das Comissóes Intersetoriais do CNS 2015/2018}

\begin{tabular}{|c|c|}
\hline $\begin{array}{l}\text { Comissóes Intersetoriais do CNS triênio } \\
\qquad 2012 / 2015\end{array}$ & $\begin{array}{l}\text { Comissóes Intersetoriais do CNS triênio } \\
\qquad 2015 / 2018\end{array}$ \\
\hline $\begin{array}{l}\text { - Comissão Intersetorial de Atenção Integral à } \\
\text { Saúde da Criança, do Adolescente e do Jovem } \\
\text { - Comissão Intersetorial da Saúde do Idoso }\end{array}$ & $\begin{array}{l}\text { - Comissão Intersetorial de Atenção à } \\
\text { Saúde nos Ciclos de Vida (Criança, } \\
\text { Adolescente, Jovem Adulto e Idoso) }\end{array}$ \\
\hline $\begin{array}{l}\text { - Comissão Intersetorial de Assistência } \\
\text { Farmacêutica } \\
\text { - Comissão Intersetorial de Ciência e Tecnologia }\end{array}$ & $\begin{array}{l}\text { - Comissão Intersetorial de Ciência, } \\
\text { Tecnologia e Assistência Farmacêutica }\end{array}$ \\
\hline $\begin{array}{l}\text { - Comissão Intersetorial de Vigilância Sanitária e } \\
\text { Farmacoepidemiologia } \\
\text { - Comissão Intersetorial de Saneamento e Meio } \\
\text { Ambiente }\end{array}$ & $\begin{array}{l}\text { - Comissão Intersetorial de Vigilância em } \\
\text { Saúde }\end{array}$ \\
\hline $\begin{array}{l}\text { - Comissão Intersetorial de Pessoas com Patologias } \\
\text { - Comissão Intersetorial de Eliminação da } \\
\text { Hanseníase } \\
\text { - Comissão Intersetorial para Acompanhamento } \\
\text { das Políticas em DST/AIDS }\end{array}$ & $\begin{array}{l}\text { - Comissão Intersetorial de Atenção à } \\
\text { Saúde de Pessoas com Patologias, DST- } \\
\text { AIDS, TB, Hanseníase e Hepatites Virais }\end{array}$ \\
\hline
\end{tabular}

continua... 


\begin{tabular}{|c|c|}
\hline $\begin{array}{l}\text { - Comissão Intersetorial de Comunicação e } \\
\text { Informação em Saúde } \\
\text { - Comissão Intersetorial de Trauma e Violência }\end{array}$ & - Comissóes extintas \\
\hline $\begin{array}{l}\text { - Comissão Intersetorial de Recursos Humanos } \\
\text { - Comissão Intersetorial de Saúde do Trabalhador } \\
\text { - Comissão Intersetorial de Alimentação e Nutrição } \\
\text { - Comissão Intersetorial de Educaçáo Permanente } \\
\text { para o Controle Social } \\
\text { - Comissão Intersetorial de Práticas Integrativas e } \\
\text { Complementares } \\
\text { - Comissão Intersetorial de Saúde Bucal } \\
\text { - Comissão Intersetorial de Saúde da Mulher } \\
\text { - Comissão Intersetorial de Saúde da Pessoa com } \\
\text { Deficiência } \\
\text { - Comissão Intersetorial de Saúde Indígena } \\
\text { - Comissão Intersetorial de Saúde Mental } \\
\text { - Comissão Nacional de Ética em Pesquisa } \\
\text { - Comissão Intersetorial de Orçamento e } \\
\text { Financiamento } \\
\text { - Comissão Intersetorial de Saúde Suplementar }\end{array}$ & - Comissóes sem alteração \\
\hline
\end{tabular}

As comissôes intersetoriais do CNS estão sob coordenação exclusiva dos atores societais sociais, com destaque, mais uma vez, para a categoria de profissionais e trabalhadores da saúde, que dirige oito comissóes. Dessa forma, constatou-se que os representantes societais sociais, além de ser maioria em número de entidade, foram os mais assíduos, coordenaram a maioria dos pontos de pautas discutidos no conselho e ocuparam a coordenação de todas as comissôes intersetoriais do CNS. Estes mesmos atores tornaram-se os responsáveis pelas principais atividades do colegiado, como: a de presidir a comissão eleitoral do CNS e o próprio conselho, conduzir a recomposição das comissóes intersetoriais e organizar e coordenar quatro conferências temáticas ocorridas no período analisado (conferência de saúde da mulher, de vigilância em saúde, de saúde do trabalhador e de comunicação em saúde).

Assim, identifica-se que, do ponto de vista da arena interna do conselho, tais atores ocupam posição predominante nesse colegiado, concentrando as atividades do CNS, sendo possível identificar seis conselheiros societais sociais que se destacam 
no plenário. Cortes et al. (2009) também mencionaram um "núcleo duro" do CNS, em torno do qual são construídas as principais estratégias de ação a serem realizadas pelos atores societais sociais. No triênio 2015/2018, esse núcleo de conselheiros é composto por quatro integrantes do Fórum dos Usuários e dois do FENTAS e é reconhecido pelo seu engajamento pelos próprios conselheiros, como pode ser notado no seguinte trecho:

Porque na verdade você tem ali 48 conselheiros de saúde, mas se você fizer uma análise, oito conselheiros dominam o conselho inteirinho, dominam no sentido de que são formadores de opinião (INFORMANTE I - GOVERNO).

\section{Dinâmica dos interesses no CNS}

A categoria de profissionais e trabalhadores da saúde está representada mediante conselhos de profissão, entidades sindicais ou, ainda, comunidade científica. Dessa forma, há profissôes que ocupam três ou quatro assentos no CNS, como ocorre com a fisioterapia, a odontologia, a enfermagem, a farmácia e a terapia ocupacional, todos com, pelo menos, uma vaga de titular. A tripla representaçấo de profissôes de saúde congregada em torno do FENTAS sugere que o protagonismo político desses conselheiros adote, como ponto de partida, o interesse legítimo do segmento em torno das causas trabalhistas, como evidenciado nas falas abaixo:

Os trabalhadores, em geral, têm uma pauta corporativa ligada ao trabalho na saúde: contra a privatização, contra a terceirização, pelo regime jurídico único, contra as OSs [Organizaçóes Sociais] (INFORMANTE I - SOCIAL).

No FENTAS se discute a pauta do CNS e o que tem afinidade com a questáo do trabalhador, a inserção do trabalhador no SUS é a bandeira principal do FENTAS, a defesa do SUS e a condição de trabalho dos trabalhadores dentro do SUS (INFORMANTE II - SOCIAL).

Grupos com interesses menos fragmentados apresentam melhores desempenhos no processo de disputa (PETINELLI, 2013). Nesse sentido, a postura corporativa do FENTAS favorece um posicionamento político mais uniforme a ser assumido por esse fórum diante do colegiado.

Os atores de mercado e governamentais, no entanto, apresentam outro perfil. Embora não se articulem através de fóruns e os conselheiros de ambas as representaçóes possam apresentar valores ético-políticos e posturas diversas, a unidade de posicionamento é mais facilmente obtida. Os primeiros, porque apresentam objetivos claros de obter e ampliar a produtividade e o lucro. E os 
segundos são indicados exatamente por ter o perfil alinhado com os interesses do poder Executivo em exercício numa dada conjuntura e, sempre que necessário, as organizaçóes estatais moldam a atuação de seus atores (AVRITZER, SOUZA, 2013). Na conjuntura atual, nota-se um alinhamento dos propósitos do governo, como o interesse econômico do mercado, como expresso nas seguintes falas:

Atores do mercado:

A gente trabalha muito para ampliar o acesso [...] aos produtos que nós fabricamos para a sociedade brasileira [...] nós temos um objetivo comum que é a melhoria da condiçáo de vida do brasileiro, sim pela livre iniciativa. Há incentivos dentro da nossa entidade para que nós tenhamos uma redução da carga tributária na saúde, é um absurdo pagar imposto sobre saúde (INFORMANTE 1 - MERCADO).

\section{Atores governamentais:}

Nesse momento o que eu sinto é que há um projeto no governo nacional muito mais voltado para o neoliberalismo [...] O que há hoje é uma mudança de projeto dentro do Ministério da Saúde, há uma mudança de prioridades e de uma visáo neoliberal muito mais forte no governo atual e, naturalmente, isto é refletido para dentro do Ministério da Saúde (INFORMANTE III - GOVERNO).

Não venha me explicar que planos de saúde de 80 reais é solução porque eu não aceito [...] É brincadeira de faz de conta, mas faz parte do negócio das pessoas que estão lá [...] essa situação de instabilidade que está aí é de assustar porque o objetivo muito claramente não é o país, é o bolso de cada um (INFORMANTE II - GOVERNO).

O Fórum dos Usuários se reúne em torno de uma plataforma múltipla de demandas cujo projeto balizador também é diverso. As falas a seguir mostram a pluralidade de pautas defendidas pelas entidades societais sociais:

O CNS é, sobretudo um lugar onde muitos [...] movimentos sociais de trabalhadores e usuários vão pra fazer disputa política de classe, de raça e de gênero. Por que isso é estruturante da desigualdade social, é estruturante da determinação social da saúde, é o que permeia o projeto político de muitos movimentos sociais e entidades de trabalhadores, vão lá fazer uma disputa de classe, vão lá fazer a disputa contra o racismo e contra o sexismo. E isso tudo pra mim, se expressa num outro conceito ou ampliar o conceito do que seja direito universal à saúde, do que seja cidadania a partir da saúde. É o lugar de afirmar o direito universal à saúde a partir do olhar dos movimentos sociais, das entidades (INFORMANTE I - SOCIAL).

Eu estou aqui para garantir políticas públicas para a saúde integral da população LGBT [...] então qualquer política pública tem que ser permeada por raça, cor, etnia, orientação intersexual e identidade de gênero (INFORMANTE IV - SOCIAL).

A gente sempre cobra que cada vez que se pensa uma política a gente consiga trazer a questão racial como transversal (INFORMANTE V - SOCIAL). 
Apesar de existir uma repetição de entidades no CNS, estas, a rigor, pautam as mesmas questôes em suas bandeiras de luta, circunstância que aponta para uma fragmentação desses movimentos (SILVA, 2016). Os tensionamentos são percebidos com vistas ao reconhecimento nas políticas de saúde das particularidades dos portadores de patologias, da população LGBTT, negra, indígena, da população de rua, dos sem-terra, sem-teto, dos estudantes, das mulheres, trabalhadores da zona rural e urbana, tornando-se difícil a consolidação de um bloco político consistente.

Tem-se que os atores integrantes do CNS não formam um grupo de interesse homogêneo. O FENTAS e o Fórum dos Usuários apresentam polarização entre a unidade política e a apresentação de pautas e demandas plurais provenientes de movimentos sociais distintos que compete na definição da tomada de posição desses fóruns a ser assumida no plenário. Mesmo assim, identifica-se uma circunstancial unificação de interesses entre os atores societais sociais, diante da conjuntura de crise enfrentada no Brasil nos anos de 2014 e 2017.

Agora a gente tem tido um diálogo muito maior [...] O Fórum de Usuários tem conseguido estar muito mais afinado e unido com Fórum de trabalhadores, isto é um momento político muito importante. Nós tínhamos fóruns que eram quase que antagônicos, quase onde um tomasse uma posição o outro tomar uma posição contrária e nós temos tido um afinamento muito grande, o diálogo entre os coordenadores dos fóruns tem proporcionado isto, uma confluência de apoio mútuo e de notar que o momento é de estar unido e não de cada um para um lado (INFORMANTE VI - SOCIAL).

\section{Considerações finais}

A composição do CNS no triênio 2015/2018 é bastante heterogênea, já que há 90 entidades nacionais representadas. No entanto, essa quantidade poderia ser maior, pois foram abertas 120 vagas no processo eleitoral que passaram a ser ocupadas pelas entidades eleitas, favorecendo a repetição das representaçóes. Observou-se, ademais, redução ainda maior na participação de outros ministérios nos assentos do CNS e que as entidades majoritárias passaram a ser as de caráter sindical, seguida das de portadores de patologias.

$\mathrm{Na}$ dinâmica de funcionamento continua existindo assimetria de poder e um núcleo de conselheiros, formado por atores societais sociais, que concentra as atividades do CNS, em detrimento dos atores governamentais e de mercado. Esse bloco hegemônico conduz o colegiado, define a tomada de posição nas pautas 
e, portanto, a direcionalidade das deliberaçôes do CNS, com destaque para o protagonismo do Fórum dos Usuários.

A análise política das disputas de poder no CNS permitiu identificar três eixos de interesses: o primeiro, relacionado à luta pelo reconhecimento; o segundo, de ampliar a obtenção de lucro no setor saúde; e o terceiro, relativo à defesa do direito universal à saúde, e do SUS constitucional (RSB). No primeiro eixo, diferenciam-se dois movimentos, o de articulação de interesses com forte viés corporativo, oriundo de entidades representativas de profissionais e trabalhadores de saúde, que buscam demonstrar a importância desses profissionais para o setor saúde; e o movimento em torno do reconhecimento das particularidades das diversas entidades nas políticas de saúde, provenientes dos grupos representados no Fórum dos Usuários.

O segundo eixo de interesses converge com a racionalidade econômica, representado explicitamente pelos atores de mercado. Os atores governamentais destacaram o alinhamento do governo com os interesses do mercado, o que aponta para a execução do papel do Estado de articulação da classe dominante. Finalmente, o terceiro eixo está representado pelo movimento afirmativo, fundado no princípio da equidade e da justiça social, identificado a partir do alinhamento político do FENTAS e do Fórum dos Usuários no plenário do CNS em torno da defesa do SUS, compelido pela atual conjuntura. Assim, a disputa não ficou restrita à tomada do poder na arena interna do colegiado. O CNS buscou ampliar o seu poder no processo decisório da política de saúde por meio de alianças estratégicas entre os fóruns.

A análise em profundidade da composição de somente um triênio do CNS consiste numa limitação do estudo, já que não permite realizar comparações com a gestão anterior do conselho. ${ }^{1}$

\section{Referências}

AVRITZER, L.; SOUZA, C. H. L. (Orgs.). Conferências nacionais: atores, dinâmicas participativas e efetividades. Brasília: IPEA, 2013.

BAHIA, L. As conferências de saúde: desafios à democracia participativa. Cad. Saúde Pública, v. 31, n. 10, p. 2047-2072, 2015.

BOLETIM OAPS. Projeto Análise de Política de Saúde (2013/2017), ano 4, ed. 15, jan.fev., 2018. Disponível em: <https://www.analisepoliticaemsaude.org/oaps/boletins/edicoes/31/\#117>. Acesso em: 15 mar. 2018. 
BRASIL. Ministério da Saúde. Conselho Nacional de Saúde. Resolução n453, de 10 de maio de 2012. Aprova as diretrizes para criação, reformulação, estruturação e funcionamento dos conselhos de saúde. Brasília, 2012.

. Decreto no 5.839, de 11 de julho de 2006. Dispóe sobre a organização, as atribuiçôes e o processo eleitoral do Conselho Nacional de Saúde - CNS e dá outras providências. Brasília: MS, 2006.

- Lei no 12.871, de 22 de outubro de 2013. Institui o Programa Mais Médicos, altera as Leis no 8.745 , de 9 de dezembro de 1993, e no 6.932, de 7 de julho de 1981, e dá outras providências. Brasília: MS, 2013.

Lei $n^{\circ}$ 8.080, de 19 de setembro de 1990. Dispóe sobre as condições para a promoção, proteção e recuperaçáo da saúde, a organização e o funcionamento dos serviços correspondentes e dá outras providências. Brasília: MS, 1990.

CAVALCANTI, M. L. T. CABRAL, M. H. P.; ANTUNES, L. R. Participação em saúde: uma sistematização de artigos publicados em periódicos brasileiros - 1988/2005. Ciências \& Saúde Coletiva, v. 17, n. 7, p. 1813-1823, 2012.

COELHO, V. S. P. Conferência Nacional de Saúde: Desafio para o país. Cad. Saúde Pública, v. 31, n. 10, p. 2047-2072, 2015.

CORTES, S. M. V. Conselhos e conferências de saúde: papel institucional e mudanças nas relaçóes entre Estado e sociedade. In: FLEURY, S.; LOBATO, L. V. C. (Orgs.). Participação, democracia e saúde. Rio de Janeiro: CEBES, 2010, p. 102-128.

CORTES, S. M. V.; SILVA, M. K.; RÉOS, J. C.; BARCELOS, M. Conselho Nacional de Saúde: histórico, papel institucional e atores Estatais e societais. In: CORTES, S. M. V. (Org.). Participação e saúde no Brasil. Rio de Janeiro: Fiocruz, 2009, p. 41-71.

COSTA, A. M. Anotaçóes sobre o artigo de Paulo Gadelha. Cad. Saúde Pública, v. 31, n. 10, p. 2047-2072, 2015.

COUTINHO, C. N. O leitor de Gramsci. Rio de Janeiro: Civilização Brasileira, 2011.

ESCOREL, S. Debate sobre o artigo de Gadelha. Cad. Saúde Pública, v. 31, n. 10, p. 20472072, 2015.

ESPIRIDIÃO, M. A. Controle social do SUS: conselhos e conferências de saúde. In: PAIM, J. S.; ALMEIDA FILHO, N. Saúde coletiva: teoria e prática. Rio de Janeiro: MedBook, 2014.

FEDERICO, L. Análise politica em saúde: a contribuição do pensamento estratégico. Salvador: EDUFBA, 2015.

FIGUEIRAS, L. Notas para a análise de conjuntura. Salvador, 2015. Disponível em: <https:// www.analisepoliticaemsaude.org/oaps/pensamentos/1827d7ce5995e6173445b8300b58 6e87/14/>. Acesso em: 19 ago. 2017. 
FRASER, N. Reconhecimento sem ética? Lua Nova, v. 70, p. 101-138, 2007.

GADELHA, P. Conferência Nacional de Saúde: desafios para o país. Cad. Saúde Pública, v. 31, n. 10, p. 2047-2072, 2015.

GOHN, M. G. Vozes que gritam e vozes silenciadas na América Latina. Civitas, v. 15, n. 3, p. 491-509, 2015.

KEZH, N. H. P.; BÓGUS, C. M.; MARTINS, C. L. Entraves à participação social dos representantes dos trabalhadores no conselho municipal de saúde. Saúde e Sociedade, v. 25, n. 4, p. 950-963, 2016.

PAIVA, F. S; STRALEN, C. J.; COSTA, P. H. A. Participação social e saúde no Brasil: revisão sistemática sobre o tema. Ciência \& Saúde Coletiva, v. 19, n. 2, p. 487-498, 2014.

PETINELLI, V. Contexto político, natureza da política, organização da sociedade civil e desenho institucional: alguns condicionantes da efetividade das conferências nacionais. In: AVRITZER, L.; SOUZA, C. H. L. (Orgs.). Conferências nacionais: atores, dinâmicas participativas e efetividades. Brasília: IPEA, 2013.

REZENDE, R. B.; MOREIRA, M. R. Relações entre representação e participação no Conselho Municipal de Saúde do Rio de Janeiro: segmento dos usuários, 2013-2014. Ciência \& Saúde Coletiva, v. 21, n. 5, p. 1409-1420, 2016.

RIBEIRO, R. Programa Mais Médicos - um equívoco conceitual. Ciência \& Saúde Coletiva, v. 20, n. 2, p. 421-424, 2015.

ROLIM, L. B.; CRUZ, R. S. B. L. C.; SAMPAIO, K. J. A. J. Participação popular e o controle social como diretriz do SUS: uma revisão narrativa. Saúde em Debate, v. 37, n. 96, p. 139-147, 2013. SILVA, B. T. Composição atual do Conselho Nacional de Saúde: questôes para debate. Disponível em: https://www.analisepoliticaemsaude.org/oaps/pensamentos/?id=87881c50c293005f1463a1 e459ce3229, 2016. Acesso em: 20 ago. 2017.

TEIXEIRA, C. F.; SILVEIRA, P. (Orgs.). Glossário de análise politica em Saúde. Salvador: EDUFBA, 2016.

TESTA, M. Pensar en salud. 3. ed. Buenos Aires: Lugar Editorial, 2004.

\section{Nota}

${ }^{1}$ B. T. da Silva elaborou o projeto de pesquisa, realizou a coleta, produção, análise e interpretaçáo dos dados, e revisou o artigo. I. M. S. O. Lima orientou o projeto de pesquisa, participou da interpretação dos dados, redigiu e revisou o artigo. 


\section{Abstract}

A political analysis of the National Health Council composition (2015/2018)

This is a political analysis of the institutions that are part of the National Health Council (CNS), elected for the triennium 2015/2018. This case study, developed at CNS, was based on Testa's strategic thinking and the concepts of state actors and societal actors. Data were produced from the analysis of documents from three sources related to the council's electoral process, to its inter-sector committees and to the minutes of the 2014-2017 meetings. In addition, the advisers were interviewed during the research period. Although the board is made up of 144 counselors, with 48 full members, a restricted core of councilors concentrates CNS main activities and influences its positioning. The analysis of power disputes in the CNS allowed the identification of interests related to the struggle for recognition, the expansion of profit making in the health sector and the defense of the constitutional SUS. Despite the plurality of interests, it was identified a political alignment between the forums regarding the defense of the SUS, seeking to broaden the power of the CNS in the decision-making process of health policy. This convergence reveals how compelled the CNS is, given the current situation of social security dismantling.

> Keywords: health councils; social participation; political analysis. 